\title{
INTESTINAL MICROFLORA
}

\section{Aberrant composition of gut microbiota of allergic infants: a target of bifidobacterial therapy at weaning?}

\author{
P V Kirjavainen, T Arvola, S J Salminen, E Isolauri
}

Gut 2002;51:51-55

Background: Recent data have outlined a relationship between the composition of the intestinal microflora and allergic inflammation, and demonstrated the competence of probiotics in downregulation of such inflammation.

Aims: Our aims were to characterise the relationship between gut microbes and the extent of allergic sensitisation and to assess whether the efficacy of bifidobacterial supplementation in the treatment of allergy could relate to modulation of the intestinal microbiota.

Methods: This randomised study included 21 infants with early onset atopic eczema of whom eight were intolerant (highly sensitised group (HSG)) and 13 tolerant (sensitised group (SG)) to extensively hydrolysed whey formula (EHF). In the SG, six were weaned to EHF without (placebo group (PG)) and seven to EHF with Bifidobacterium lactis Bb-12 supplementation (bifidobacteria treated group (BbG)).

See end of article for authors' affiliations

....................

Correspondence to: P V Kirjavainen, Functional Foods Forum, University of Turku, FIN-20014 Turku, Finland;

pirkka.kirjavainen@utu.fi

Accepted for publication 2 October 2001 The faecal microflora of infants in the HSG was analysed only before weaning whereas in the SG the faecal microflora was analysed both before and after weaning.

Results: Infants in the HSG had greater numbers of lactobacilli/enterococci than those in the SG. Serum total lgE concentration correlated directly with Escherichia coli counts in all infants and with bacteroides counts in the HSG, indicating that the presence of these bacteria is associated with the extent of atopic sensitisation. The effect of supplementation was characterised as a decrease in the numbers of Escherichia coli and protection against an increase in bacteroides numbers during weaning.

Conclusions: These data indicate that bifidobacterial supplementation appears to modify the gut microbiota in a manner that may alleviate allergic inflammation. Further studies are needed to confirm this conclusion.
$\mathrm{P}$ robiotic therapy appears to alleviate allergic inflammation demonstrated as control of clinical symptoms and reduction of local and systemic inflammatory markers. ${ }^{12}$ On the basis of experimental data, the mechanisms behind these outcomes may involve enhanced antigen elimination ${ }^{3-7}$ and downregulated inflammatory responses via direct effects on the immune system ${ }^{124-12}$ as well as effects seen as modified degradation, permeation, and presentation of food antigens. ${ }^{13-16}$

The mechanisms of the probiotic action may be mediated via effects on the microbial composition and metabolic activity of the intestinal flora. ${ }^{17}$ Infants with food allergies have been reported to have a disturbed balance between beneficial and potentially harmful bacteria in the large intestine. ${ }^{18-21}$ Such flora may provide a means for the initiation or perpetuation of allergic inflammation. Indeed, there are data to suggest that an aberrant microbial composition in the gut such as inadequate bifidobacterial biota may deprive the developing immune system from counterregulatory signals against $\mathrm{T}$ helper 2 mediated allergic responses. ${ }^{192123}$ Conversely, by triggering inflammatory responses or by toxin formation, some bacteria may increase gut permeability and thus exposure to potential allergens. ${ }^{17}{ }^{24-27}$ Of the predominant bacterial groups in infancy, some strains of Escherichia coli, bacteroides, and clostridia have such properties ${ }^{28-30}$ and were therefore counted in the present study.

Substantial compositional changes in the intestinal microflora occur during weaning. ${ }^{31}$ In this study our primary aim was to test whether the proven efficacy of a probiotic therapy to alleviate allergic inflammation during this period ${ }^{2}$ could be associated with modifications to the microbiota. Also, the relationship between allergic sensitisation and composition of the microbiota was further evaluated.

\section{METHODS}

\section{Subjects and study design}

The study population comprised 21 infants from a cohort of 100 infants with early onset atopic eczema and/or gastrointestinal symptoms, family history of atopic disorders, and failure to thrive, as previously described. ${ }^{32}$ We selected infants with a heightened risk of chronic allergic disease. They fulfilled the Hanifin criteria for atopic eczema during exclusive breast feeding ${ }^{33}$ and had never been given any infant formula. At weaning, they $(n=35)$ were randomised in a double blind manner to receive extensively hydrolysed whey formula (EHF; Valio Ltd., Helsinki, Finland) with (bifidobacteria treated group $(\mathrm{BbG})$ ) or without (placebo group $(\mathrm{PG}))$ probiotic supplementation.

The clinical symptoms of 5/15 infants in the PG and 10/20 infants in the BbG were not improved; sustained symptoms included pruritus, eczema, gastrointestinal symptoms (such as loose stools, gas, and vomiting) and subjective symptoms reported by parents (for example, crying and restlessness). For ethical reasons weaning of these infants was continued with an amino acid derived formula (SHS International Ltd, Liverpool, UK) instead of EHF, as previous studies have identified that infants manifesting atopic eczema during breast feeding may be intolerant to EHF, possibly in response to the presence of residual milk proteins and/or aggregated or cross linked low

Abbreviations: $\mathrm{BbG}$, bifidobacteria treated group; $\mathrm{EHF}$, extensively hydrolysed whey formula; FISH, fluorescence in situ hybridisation; HSG, highly sensitised group; IQR, interquartile range; LPS, lipopolysaccharide; PBS, phosphate buffered saline; PG, placebo group; SG, sensitised group. 
molecular weight peptides. ${ }^{34-38}$ These infants who were apparently intolerant to EHF are hereafter referred to as the highly sensitised group (HSG) and the infants who tolerated EHF as the sensitised group (SG).

Faecal samples were collected from infants in both the HSG and SG before weaning (that is, during exclusive breast feeding) at a mean (interquartile range (IQR)) age of 5.2 (4.2-6.0) months, and after weaning at a mean age of 9.1 (7.8-10.5) months only in the SG. All infants whose faecal samples did not contain enough biomass for quantitative microbiological assessments were excluded from the study; the number of infants included in each group is presented in table 1 .

The extent of sensitisation was evaluated by serum total IgE (Phadebas IgE Prist; Pharmacia, Uppsala, Sweden) and the severity of atopic eczema by the SCORAD method when faecal samples were collected. ${ }^{39}$ At enrolment, median (IQR) serum total IgE concentration in the HSG was $11(0-18) \mathrm{kU} / \mathrm{l}$ and SCORAD score $22(12-25)$, and in the SG, 12 (6-23) kU/l and 9 (5-16), respectively. During weaning, cow's milk allergy was confirmed in 6/8 infants in the HSG and in 6/13 infants in the SG by a double blind placebo controlled challenge, as previously described. ${ }^{32}$ The SCORAD score decreased in $3 / 6$ infants in the PG and in 7/7 infants in the BbG (Fisher's exact $p=0.07$ ), supporting the previously published clinical report with a larger study population. ${ }^{2}$

The study protocol was approved by the Tampere University Hospital Committee on Ethical Practice and written informed consent to participate was obtained from the children's parents

\section{Probiotic supplementation}

EHF was supplemented with Bifidobacterium lactis Bb-12 (Christian Hansen A/S, Hørsholm, Denmark) in a concentration of $1 \times 10^{9}$ colony forming units/g. A bifidobacterium strain was chosen for probiotic supplementation as bifidobacteria are considered important for infant health and suggested to be associated with a reduced risk of developing atopy. ${ }^{19}{ }^{40}$ Bifidobacterium lactis $\mathrm{Bb}-12$ was originally isolated from the faeces of a healthy adult. This strain was selected due to its documented safety and efficacy in the prevention of rotavirus diarrhoea and strong in vitro adhesion properties indicative of the ability of temporary colonisation..$^{41-43}$ The dose was chosen based on studies on the required dose of probiotics in the prevention of diarrhoea. ${ }^{41}{ }^{44-46}$

An independent microbiologist controlled the bacterial concentration using a standard plate count method. The formula was stored under dry and cool conditions. No significant decreases were observed in the numbers of bacteria in the test formulas during storage. Formula intake was assessed as previously described ${ }^{2}$ and the mean daily intake of Bb-12 during the study period was defined as $8 \times 10^{10}$ (range $6-11 \times 10^{10}$ ) colony forming units/kg body weight.

\section{Analysis of the bacteriology of faecal samples using genetic probes}

Parents scraped faecal specimens from the diapers after defecation. The specimens were immediately cooled at $6-8^{\circ} \mathrm{C}$, delivered within 24 hours, and frozen at $-75^{\circ} \mathrm{C}$ directly on receipt. Bacterial cells were harvested and fixed, and fluorescence in situ hybridisation (FISH) performed with fluorophore (indocarbocyanin $\mathrm{Cy} 3$ ) labelled oligonucleotide probes, as previously described. ${ }^{19} 47$ Bifidobacteria were counted with probe BIFl64 ('5-CATCCGGCATTACCACCC), bacteroides with BAC303 ('5-CCAATGTGGGGGACCTT), lactobacilli/enterococci with LAB158 ('5-GGTATTAGCA(T/ C)CTGTTTCCA) ${ }^{49}$ clostridia belonging to the Clostridium histolyticum group with HIS150 ('5-TTATGCGGTATTAATCT(C/ T)CCTTT), ${ }^{50}$ and Escherichia coli with EC1531 ('5CACCGTAGTGCCTCGTCATCA).$^{51}$ The probe HIS 150 detects a representative proportion of the known clostridia species

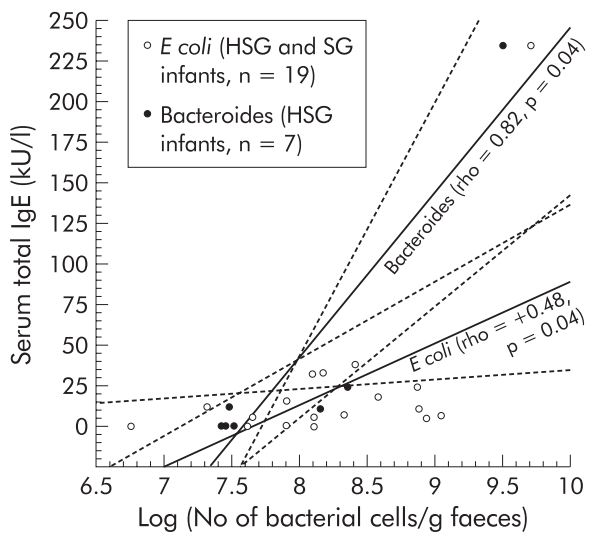

Figure 1 Scattergram showing faecal concentrations of bacteroides and Escherichia coli versus serum total lgE concentration in each individual. Regression lines with $95 \%$ confidence intervals (broken lines); Spearman's rho and $p$ values are given for both slopes. HSG, highly sensitised group; SG, sensitised group.

commonly present in the infant gut-for example, Clostridium paraputrificum, Clostridium butyricum, and Clostridium perfringens but not Clostridium difficile. ${ }^{52}$ All probes used in this study are among the best validated and most widely used oligonucleotide probes for FISH based analysis of faecal bacterial flora. ${ }^{50}{ }^{53}$ Total cell numbers were counted using a nucleic acid stain 4',6-diamidino-2-phenylindole. Cells were counted visually using a Leica Laborlux D epifluorescence microscope.

\section{Statistics}

We estimated that a total of 12 subjects were required for parallel comparisons of faecal bacterial numbers in the two groups to detect a difference at a two sided 5\% significance level with over $80 \%$ probability if the true difference between the group means was at least $1 \log .^{54}$ This was based on the assumption that the standard deviation of the mean in bacterial numbers is $0.5 \mathrm{log}$, as indicated by preliminary observations.

Bacterial numbers are presented as median number of bacterial cells per gram of faeces (with IQR). Changes in bacterial numbers in faeces, which followed the intervention with infant formula, are presented as medians of relative changes: ((number of bacteria after weaning-number of bacteria before weaning)/the number of bacteria before weaning) $\times 100 \%$ ). The Mann-Whitney test was used to analyse intergroup differences in the bacterial flora between the SG and HSG before weaning as well as the relative changes between the PG and BbG during weaning. These changes were also analysed by Fisher's exact test to compare whether bacterial numbers tented to increase/decrease more frequently within the PG or BbG. Intragroup responses to weaning were analysed by the Wilcoxon signed rank test. The Spearman rank correlation (expressed as rho, describing linear relationships between two variables) was calculated to study the relationships between cell counts of different bacterial groups, serum total IgE, and SCORAD scores. Differences with $\mathrm{p}$ values $<0.05$ are reported as statistically significant. All analyses, except for the sample size calculation, were performed using computer software StatView for Windows version 4.5.7 (SAS Institute Inc., Cary, North Carolina, USA)

\section{RESULTS}

Gut microflora and the extent of allergic sensitisation

To evaluate whether the gut microbiota was associated with allergic sensitisation, the faecal flora before weaning was compared between the HSG and SG (table 1). Within the HSG, the lactobacilli/enterococci counts were significantly 
Table 1 Bacterial numbers between infants in the highly sensitised group (HSG) and sensitised group (SG) before weaning, as well as changes in bacterial numbers in the SG during weaning, comparing the bifidobacteria treated group $(\mathrm{BbG})$ and the placebo group $(\mathrm{PG})$

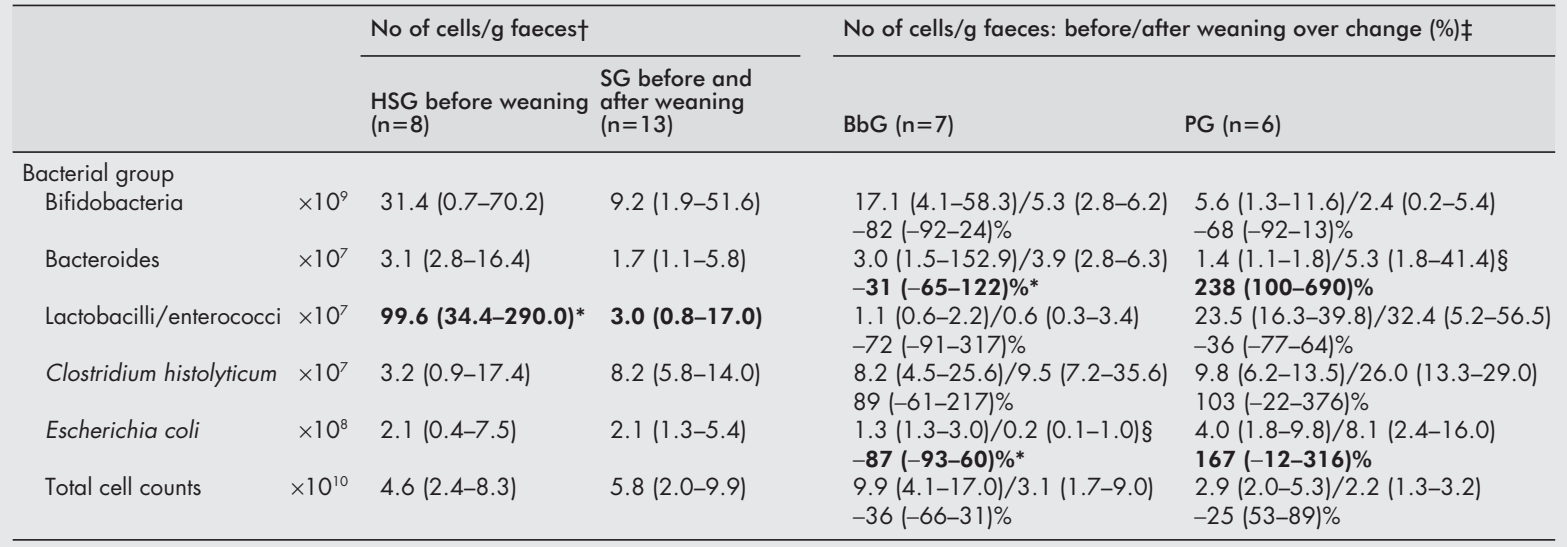

†All values are expressed as group medians (interquartile range).

$¥$ The change \% expresses the change during weaning relative to the number of bacteria before weaning.

* Significant difference from the respective values compared (in bold) at $p<0.05$.

$\S$ Bacterial numbers after weaning were significantly ( $p=0.04$ for bacteroides and 0.02 for $E$ coli) different from those during breast feeding.

$(\mathrm{p}=0.002)$ higher than in the SG. In the HSG, the faecal concentration of bacteroides correlated directly with the total concentration of IgE in serum (fig l) but not in the SG (rho= $-0.28, p=0.35)$. In the whole study population $(n=19)$, the total concentration of IgE in serum correlated directly with the numbers of $E$ coli in faeces (fig 1).

\section{Effects of bifidobacterial supplementation on the gut microbiota}

The response of the digestive microflora to bifidobacterial supplementation was studied by comparing changes in the faecal microbial composition during weaning between the PG and $\mathrm{BbG}$. As illustrated in table 1 , the changes in the bacteroides and $E$ coli flora were significantly $(\mathrm{p}<0.05)$ different between these infant groups. Within the PG, the faecal bacteroides numbers increased in all, and $E$ coli numbers in $4 / 6$ infants, while in the BbG bacteroides numbers decreased in $4 / 7$ and $E$ coli numbers in all infants ( $\mathrm{p}=0.07$ and 0.02 , respectively, for bacteroides and $E$ coli).

\section{DISCUSSION}

Bifidobacterial supplementation prevented the increase in the numbers of bacteroides and $E$ coli during weaning, which is in agreement with previous in vitro and clinical data. ${ }^{55-58}$ We postulate that this effect may be part of the mechanism by which bifidobacterial supplementation alleviates atopic eczema. ${ }^{2} \mathrm{~A}$ similar effect may also contribute to the protective effect exclusive breast feeding has been suggested to have in high risk infants $s^{59}$; the gut flora of breast fed neonates is essentially dominated by bifidobacteria while formula fed infants exhibit a more complex flora with relatively high numbers of bacteroides and $E$ coli. ${ }^{53}$

In support of our postulation, in the present study high numbers of bacteroides and $E$ coli were associated with the extent of atopic sensitisation. Whether $E$ coli and bacteroides may actually promote atopic sensitisation remains to be verified. Our recent data tentatively attest to this possibility. In one study comprising 15 infants with early onset atopic eczema, those six who were later diagnosed as allergic to cow's milk tended to have the highest bacteroides counts during exclusive breast feeding. ${ }^{21}$ Our unpublished data on 69 infants with cow's milk allergy showed that of those infants who had a detectable concentration of IgE in serum, 74\% (36/51) had $E$ coli as part of their most predominant culturable aerobic flora during breast feeding while among infants in whom serum IgE was not detected the respective value was only $39 \%$ (7/18) (Kirjavainen et al, unpublished). Conversely, others have shown that oral introduction of a non-enteropathogenic $E$ coli strain after birth can reduce the risk of developing allergic disease. ${ }^{60}$ This discrepancy is in agreement with previous evidence suggesting that the endotoxin lipopolysaccharide (LPS) reduces the risk of development of atopic disease by stimulating Thl cells while in asthmatic patients LPS aggravates bronchial inflammation and thus the symptoms of the disease. ${ }^{27}$ Similarly, in infants with atopic eczema, E coli (for example, due to LPS) may evoke an inflammatory response in the gut leading to increased allergen uptake and thereby greater atopic sensitisation.

The higher lactobacilli/enterococci counts in the HSG than in the SG tentatively demonstrates an association between these bacterial genera and the extent of allergic sensitisation. This suggestion is in agreement with our previous data demonstrating a direct correlation between lactobacilli/enterococci counts and serum total IgE concentration in atopic infants who had been weaned to amino acid derived infant formula. A number of other studies however have found that lactobacilli are associated with beneficial effects in the management of atopic eczema ${ }^{1261}$ and cow's milk allergy. ${ }^{94-16}$ On this basis it seems unlikely that robust lactobacillar flora would have allergic sensitisation promoting properties. Some species of enterococci have virulence factors that can compromise the gut barrier and in theory could thereby affect atopic sensitisation but to our knowledge no previous data have been reported that would support this theory. ${ }^{62}$ A conceivable explanation is that allergic sensitisation promotes the growth of lactobacilli and/or enterococci by causing changes in the gut ecology. Such an effect could be secondary to the disease; for example, the increase in the numbers of oral lactobacilli in asthmatic children has been suggested to be a response to their medication. ${ }^{63}$

In conclusion, bifidobacterial supplementation modulates the composition of the gut microbiota during weaning in a manner that could contribute to alleviation of the symptoms of atopy. The desirable modifications were identified as restraining of bacteroides and $E$ coli flora, but unexpectedly also the desirability of a robust lactobacillar/enterococcal flora was called into question. Detailed analyses of the microbial composition of allergic infants at different ages and at the 
species level are needed for a better understanding of the significance of the microbiota associated abnormalities in allergy. Such studies should also provide the means for more accurate targeting and thus more effective and better controlled modulation of the microbial milieu.

\section{ACKNOWLEDGEMENTS}

We wish to acknowledge the help of Tuija Poussa, MSc, as a statistical consultation. The project was supported by the Academy of Finland.

\section{Authors' affiliations}

P V Kirjavainen, S J Salminen, Department of Biochemistry and Food Chemistry, University of Turku, Finland

T Arvola, Department of Paediatrics, Tampere University Hospital,

Tampere, Finland

E Isolauri, Department of Paediatrics, Turku University Hospital, Turku, Finland

\section{REFERENCES}

1 Majamaa $\mathrm{H}$, Isolauri E. Probiotics: a novel approach in the management of food allergy. J Allergy Clin Immunol 1997;99:179-85.

2 Isolauri E, Arvola T, Sütas Y, et al. Probiotics in the management of atopic eczema. Clin Exp Allergy 2000;30:1604-10.

3 Moreau MC, Ducluzeau R, Guy-Grand D, et al. Increase in the population of duodenal $\lg \mathrm{A}$ plasmocytes in axenic mice monoassociated with different living or dead bacterial strains of intestinal origin. Infect Immun 1978;21:532-9

4 de Simone C, Ciardi A, Grassi A, et al. Effect of Bifidobacterium bifidum and Lactobacillus acidophilus on gut mucosa and periphera blood B lymphocytes. Immunopharmacol Immunotoxicol 1992; 14:331-40

5 Kaila $M$, Isolauri $E$, Soppi $E$, et al. Enhancement of the circulating antibody secreting cell response in human diarrhoea by a human Lactobacillus strain. Pediatr Res 1992:32:141-4.

6 Yasui $\mathbf{H}$, Nagaoka N, Mike A, et al. Detection of Bifidobacterium strains that induce large quantities of IgA. Microb Ecol Health Dis 1992;5:155-62

7 Majamaa $\mathbf{H}$, Isolauri $E$, Saxelin $M$, et al. Lactic acid bacteria in the treatment of acute rotavirus gastro-enteritis. J Pediatr Gastroenterol Nutr 1995;20:333-8

8 Matsuzaki T, Yamazaki R, Hashimoto S, et al. The effect of oral feeding of Lactobacillus casei strain Shirota on Immunoglobulin E production in mice. J Dairy Sci 1998:81:48-53.

9 Pelto L, Isolauri E, Lilius E-M, et al. Probiotic bacteria down-regulate the milk-induced inflammatory response in milk-hypersensitive subjects but have an immunostimulatory effect in healthy subjects. Clin Exp Allergy 1998;28: 1474-9.

10 Shida K, Makino K, Morishita A, et al. Lactobacillus casei inhibits antigen-induced $\lg E$ secretion through regulation of cytokine production in murine splenocyte cultures. Int Arch Allergy Immunol 1998; 115:278-87

11 Takahashi T, Nakagawa E, Nara T, et al. Effects of orally ingested Bifidobacterium longum on the mucosal lgA response of mice to dietary antigens. Biosci Biotechnol Biochem 1998;62:10-15.

12 Kankaanpää $\mathbf{P}$, Sütas $Y$, Arvilommi H, et al. Comparison of antiproliferative effects of probiotic cell extracts and glucocorticoids. Gastroenterol Int 1998;11:S139.

13 Dahlgren UIH, Wold AE, Hanson LA, et al. Expression of a dietary protein in $E$. coli renders it strongly antigenic to gut lymphoid tissue. Immunology $1991 ; 73: 394-7$.

14 Isolauri E, Majamaa H, Arvola T, et al. Lactobacillus casei strain GG reverses increased intestinal permeability induced by cow milk in suckling rats. Gastroenterology 1993;105: 1643-50.

15 Sütas $Y$, Hurme M, Isolauri E. Down-regulation of anti-CD3 antibody-induced IL-4 production by bovine caseins hydrolysed with Lactobacillus GG-derived enzymes. Scand J Immunol 1996;43:687-9.

16 Sütas Y, Soppi E, Korhonen H, et al. Suppression of lymphocyte proliferation in vitro by bovine caseins hydrolysed with Lactobacillus casei GG-derived enzymes. J Allergy Clin Immunol 1996;98:2 16-24.

17 Kiriavainen PV, Apostolou E, Salminen SJ, et al. New aspects of probiotics-a novel approach in the management of food allergy. Allergy 1999;54:909-15.

18 Bjorksten B, Naaber P, Sepp E, et al. The intestinal microflora in allergic Estonian and Swedish 2-year-old children. Clin Exp Allergy 1999;29:342-6

19 Kalliomäki $M$, Kirjavainen $P$, Eerola $E$, et al. Distinct patterns of neonatal gut microflora in infants developing or not developing atopy. $J$ Allergy Clin Immunol 2001;107:129-34.

20 Bjorksten B, Sepp E. Julge K, et al. Allergy development and the intestinal microflora during the first year of life. Allergy Clin Immunol $2001 ; 108: 516-20$

21 Kiriavainen PV, Apostolou E, Arvola T, et al. Characterizing the composition of intestinal microflora as a prospective treatment target in inflant allergic disease. FEMS Immunol Med Microbiol 2001;32:1-7.
22 Sudo N Sawamura S, Tanaka K, et al. The requirement of intestinal bacterial flora for the development of an lgE production system fully susceptible to oral tolerance induction. J Immunol 1997;159:1739-45

23 Hessle C, Andersson B, Wold AE. Gram-positive bacteria are potent inducers of monocytic interleukin-12 (IL-12) while gram-negative bacteria preferentially stimulate IL-10 production. Infect Immun 2000;68:3581-6.

24 Duchmann R, Kaiser E, Hermann E, et al. Tolerance exists towards resident intestinal flora but is broken in active inflammatory bowel disease (IBD). Clin Exp Immunol 1995; 102:448-55.

25 Salminen S, Bouley C, Boutron-Ruault $M-C$, et al. Functional food science and gastrointestinal physiology and function. $\mathrm{Br} J$ Nutr 1998;80:S147-71.

26 Neish AS, Gewirtz AT, Zeng H, et al. Prokaryotic regulation of epithelial responses by inhibition of IKB- $\alpha$ ubiquitination. Science 2000;289: 1560-63.

27 Lapa e Silva JR, Possebon da Silva MD, Lefort J, et al. Endotoxins, asthma, and allergic immune responses. Toxicology 2000:152:31-5.

28 Deitch EA, Specian RD, Berg RD. Endotoxin-induced bacterial translocation and mucosal permeability: role of xanthine oxidase, complement activation, and macrophage products. Crit Care Med $1991 ; 19: 785-91$.

29 Obiso RJ Jr, Lyerly DM, Van Tassell RL, et al. Proteolytic activity of the Bacteroides fragilis enterotoxin causes fluid secretion and intestinal damage in vivo. Infect Immun 1995;63:3820-6.

$30 \mathrm{McDonel}$ JL. The molecular mode of action of Clostridium perfringens enterotoxin. Am J Clin Nutr 1979;32:210-18.

31 Stark PL, Lee A. The microbial ecology of the large bowel of breast-fed and formula-fed infants during the first year of life. J Med Microbiol 1982;15:189-203.

32 Isolauri E, Tahvanainen A, Peltola T, et al. Breast-feeding of allergic infants. J Pediatr 1999;134:27-32.

33 Hanifin JM. Epidemiology of atopic dermatitis. Monogr Allergy 1987;21:116-31

34 de Boissieu D, Matarazzo P, Dupont C. Allergy to extensively hydrolysed cow milk proteins in infants: identification and treatment with an amino acid-based formula. J Pediatr 1997;131:744-7.

35 Vanderhoof JA, Murray ND, Kaufman SS, et al. Intolerance to protein hydrolysate infant formulas: an underrecognised cause of gastrointestinal symptoms in infants. J Pediatr 1997;131:741-4.

36 Isolauri E, Sütas Y, Salo MK, et al. Elimination diet in cow's milk allergy: risk for impaired growth in young children. J Pediatr 1998;132:1004-9.

37 Isolauri E, Sütas Y, Mäkinen-Kiljunen S, et al. Efficacy and safety of hydrolysed cow milk and amino acid-derived formulas in infants with cow milk allergy. J Pediatr 1995;127:550-7.

38 Makinen-Kiljunen S, Sorva R. Bovine beta-lactoglobulin levels in hydrolysed protein formulas for infant feeding. Clin Exp Allergy 1993;23:287-91

39 European Task Force on Atopic Dermatitis. Severity scoring of atopic dermatitis: The SCORAD Index. Dermatology 1993;186:23-31.

40 Ballongue J. Bifidobacteria and probiotic action. In: Salminen S, Wright A, eds. Lactic acid bacteria. Microbiology and functional aspects. New York: Marcel Dekker, 1998:519-87.

41 Saavedra JM, Bauman NA, Oung I, et al. Feeding of Bifidobacterium bifidum and Streptococcus thermophilus to infants in hospital for prevention of diarrhoea and shedding of rotavirus. Lancet 1994;344:1046-9.

42 Kirjavainen PV, Ouwehand AC, Isolauri E, et al. The ability of probiotic bacteria to bind to human intestinal mucus. FEMS Microbiol Lett 1998; 167: 185-9.

43 Juntunen M, Kirjavainen PV, Ouwehand AC, et al. Adherence of probiotic bacteria to human intestinal mucus in healthy infants and during rotavirus infection. Clin Diagn Lab Immunol 2001:8:293-6.

44 Siitonen S, Vapaatalo H, Salminen S, et al. Effect of Lactobacillus GG yoghurt in prevention of antibiotic associated diarrhoea. Ann Med 1990:22:57-9.

45 Saxelin M, Elo S, Salminen S, et al. Dose response colonisation of faeces after oral administration of Lactobacillus casei strain GG. Microbiol Ecol Health Dis 1991;4:209-14.

46 Goldin B, Gorbach S, Saxelin M, et al. Survival of Lactobacillus species (strain GG) in human gastrointestinal tract. Dig Dis Sci 1992;37:121-8.

47 Langendijk PS, Schut F, Jansen GJ, et al. Quantitative fluorescence in situ hybridisation of Bifidobacterium spp. with genus-specific 16S rRNA-targeted probes and its application in faecal samples. Appl Environ Microbiol 1995;61:3069-75.

48 Manz W, Amann R, Ludwig W, et al. Application of a suite of 16S rRNA-specific oligonucleotide probes designed to investigate bacteria of the phylum cytophaga-flavobacter-bacteroides in the natural environment. Microbiology 1996;142:1097-106.

49 Harmsen HJM, Elfferich P, Schut F, et al. A 16 S rRNA-targeted probe for detection of lactobacilli and enterococci in faecal samples by fluorescent in situ hybridisation. Microbiol Ecol Health Dis $1999 ; 11: 3-12$

50 Harmsen HJM, Gibson GR, Elfferich P, et al. Comparison of the plate culture technique and fluorescence in situ hybridisation using specific rRNA-based probes for the quantification of human faecal bacteria. FEMS Microbiol Lett 2000;183:125-9.

51 Poulsen LK, Licht TR, Rang C, et al. Physiological state of E. coli BJ4 growing in the large intestines of streptomycin-treated mice. J Bacteriol 1995; 177:5840-5.

52 Stark PL, Lee A. Clostridia isolated from the faeces of infants during the first year of life. J Pediatr 1982;100:362-5.

53 Harmsen HJM, Wildeboer-Veloo ACM, Raangs GC, et al. Analysis of intestinal flora development in breast-fed and formula-fed infants by using 
molecular identification and detection methods. J Pediatr Gastr Nutr 2000:30:61-7.

54 Sokal RR, Rohlf FJ. Biometry. New York: WH Freeman and Co, 1981

55 Gibson GR, Wang X. Regulatory effects of bifidobacteria on the growth of the other colonic bacteria. J Appl Bacteriol 1994;77:412-20.

56 Bernet MF, Brassart D, Neeser JR, et al. Adhesion of human

bifidobacterial strains to cultured human intestinal epithelial cells and inhibition of enteropathogen-cell interactions. Appl Environ Microbiol 1993;59:4121-8.

57 Fujiwara S, Hashiba H, Hirota T, et al. Proteinaceous factor(s) in culture supernatant fluids of bifidobacteria which prevents the binding of enterotoxigenic Escherichia coli to gangliotetraosylceramide. Appl Environ Microbiol 1997;63:506-12.

58 Benno Y, Mitsuoka T. Impact of Bifidobacterium longum on human faecal microflora. Microbiol Immunol 1992;36:683-94.
59 Committee on Nutrition. Hypoallergenic infant formulas. Pediatrics 2000;106:346-9.

60 Lodinová- Žádníková R, Cukrowská B. Influence of oral colonization of the intestine with a non-enteropathogenic $E$. coli strain after birth on the frequency of infectious and allergic diseases after 10 and 20 years. Immunol Lett 1999;69:64.

61 Kalliomaki M, Salminen S, Arvilommi H, et al. Probiotics in primary prevention of atopic disease: a randomised placebo-controlled trial. Lancet 2001;357:1076-9.

62 Franz CM, Holzapfel WH, Stiles ME. Enterococci at the crossroads of food safety? Int J Food Microbiol 1999;47:1-24.

63 Ryberg M, Moller C, Ericson T. Saliva composition and caries development in asthmatic patients treated with beta 2-adrenoceptor agonists: a 4-year follow-up study. Scand J Dent Res 1991;99:212-8.

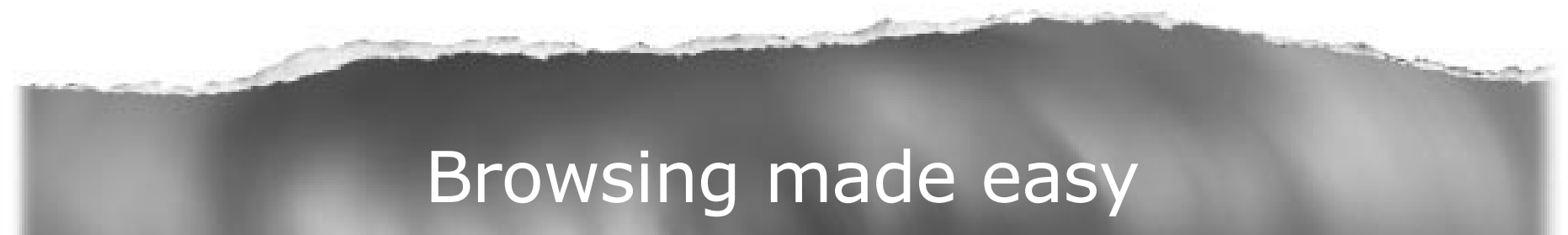

\section{Collections}

With a single click Collections allows you to find all articles that have been published in your chosen subject. Select from over 200 clinical and non-clinical topic collections and/or cross search other specialist journals, the BMJ and Cochrane Reviews

\section{www.gutjnl.com}

